\title{
Reducing Rural-Urban Education Gap in Uganda Through ICT Appropriate Technology
}

\author{
Hyosun Roh ${ }^{\dagger}$ \\ Department of Vocational Training, Reformed Theological College, Republic of Uganda \\ 우간다의 도시-농촌 간 교육 불균형 해소를 위한 ICT 적정기술 \\ 노효선 $^{\dagger}$ \\ 우간다 개혁신학대 직업훈련학과, 우간다 캄팔라
}

\begin{abstract}
동아프리카에 속한 우간다도 농업 중심의 현 국가 상황에서 벗어나 중상위권 국가로 도약하기 위해 다양한 국가개발 계획을 세우고 진행하고 있다. 그러나 다양한 정부의 노력에도 도시-농촌간 균형적인 발전을 이루지 못하고 그 격차 가 더욱 심화되고 있다. 특별히 도시-농촌간 교육 격차는 장기적으로 우간다 국가계발 계획에 부정적인 영향을 줄 수 있는 문제점으로 부각되고 있다. 본 논문에서는 우간다의 도시-농촌간 교육 불균형이 가속화되고 있는 원인들을 살펴 보고 전자도서관 시스템과 같은 ICT 적정 기술을 활용하여 교육 불균형을 감소 시킬 수 있는 방안을 소개하고자 한다.

The government of Uganda, which belongs to East Africa, approved the National Vison Statement, "A transformed Ugandan society from a Peasant to a Modern and Prosperous Country within 30 years". However, the Uganda is facing the problem of unbalanced development between urban and rural area in spite of the government's efforts. In particular, the urban-rural education gap is emerging as a problem that could negatively affect national development plans. In this paper, we explain the reasons why Uganda's urban-rural educational imbalance is accelerating. In addition, we would like to introduce a way to reduce the educational imbalance by using appropriate technology of ICT such as the electronic library system.
\end{abstract}

KEYWORDS: IT4U (Information Technology for Uganda), RACHEL (Remote Area Community Hotspot for Education and Learning), WAINBOX (Worldwide Academy in a Box)

\section{서론}

여러 아프리카 국가들은 현재의 상황을 벗어나 중상위권 국가들로 도약하기 위해 다양한 중장기 국가 발전 계획들 을 세우고 있다. 그러나 그들의 노력에도 불구하고 불안한 정치, 경제 문제로 수년째 제자리걸음을 하고 있거나, 뒷걸 음질하는 국가들도 여럿 존재한다. 우간다 또한 2007년 'Uganda Vision 2040'이라는 중장기 국가 발전 계획을 세우

\footnotetext{
†To whom correspondence should be addressed.

E-mail: peterhyo@gmail.com

Received: 127 April 2021, Revised : 21 May 2021,

Accepted: 25 May 2021
}

고 농업국가에서 현대화된 중상위 국가로 도약하기 위해 다 양한 국가사업을 진행하고 있다(NPA, 2002). 이러한 노력의 결과로 수년 전에 비해 다양한 영역에서 국가 발전을 이루 어가고 있지만 대부분이 도시지역에 집중되어 있어 도시, 농 촌 간에 다양한 형태의 불균형이 관찰되고 있다.

여기서는 다양한 불균형 중 도시-농촌 간 교육 불균형과 이러한 불균형이 생긴 원인에 대해서 설명하고 도시-농촌 간 교육 불균형을 줄이기 위해 지원하고 있는 ICT 적정기 술을 소개하고자 한다.

\section{우간다 개요}

우간다는 적도에 위치한 중동부 아프리카에 속한 내륙 국 


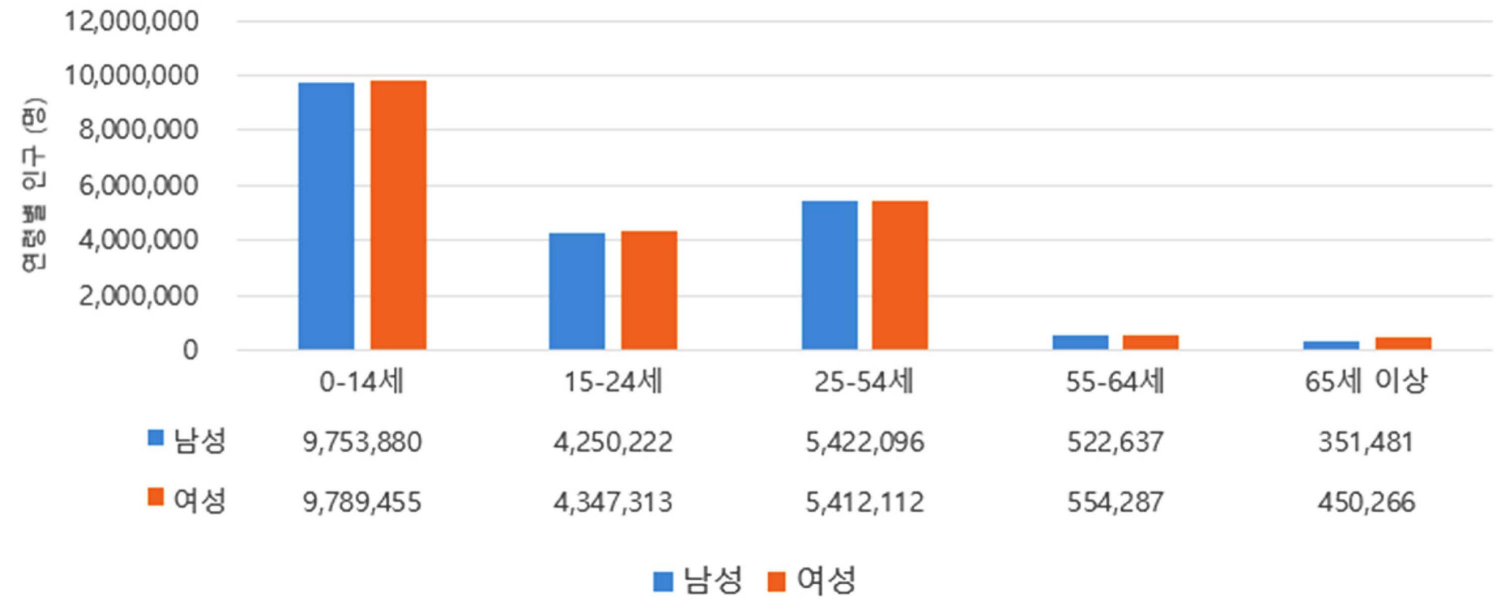

Figure 1. 연령별 인구 비율

가로 1890 년 영국, 독일 간 베를린 조약에 의해 영국 식민 지가 되었다가 1962년 10월 9일 독립하였다. 우간다는 평 균 해발 고도 $1,200 \mathrm{~m}$ 에 위치한 고원지대로 연교차가 거의 없고, 인구 4,420 만, 국토 크기는 남한의 2.4 배 $\left(241,038 \mathrm{~km}^{2}\right)$ 로 5년 임기 대통령중심제의 정부형태를 가진 국가이다. 또 한, 32 개의 부족으로 이루어진 국가로 언어는 영어와 스와 힐리어를 공용어로 사용하고 있지만 부족들이 모여 사는 지 역에서는 부족어를 사용하고 있다. 수도는 우간다 남부에 위 치한 캄팔라 (Kampala)이고 가까운 도시인 엔테베 (Entebbe) 에 우간다 국제공항이 있다. 현재 우간다는 1986년 1월 취 임한 무세베니 (Museveni, Y.) 대통령이 2021년 1월 대선에 서 6선에 성공하면서 35년 넘게 장기집권을 하고 있다.

우간다는 Figure 1에서와 같이 전체 인구 가운데 0 24세 인구 비율이 $68.9 \%$ (2019년 기준)이고 15 54세까지 인구 비 율은 44.4\% (2019년 기준)로 매우 젊은 국가임을 알 수 있 다(The World Bank, 2021a). 근로인력이 풍부한 국가이지만 실업률은 $9.4 \%$ 정도이고 15 24세 실업률이 $14.4 \%$ 이다. 다 음의 Table 1 에서와 같이 우간다의 산업별 노동인구를 살펴 보면 농업인구가 $71 \%$ (어업, 임업 포함)로 가장 많고 서비 스 산업인구가 $22 \%$ (공무원, 통신 서비스, 운송, 금융 서비 스 등이 포함됨)이고 산업인구는 $7 \%$ (광업, 제조업, 에너지 생산, 건설업)로 매우 낮은 것을 알 수 있다. 즉, 우간다에 는 일할 수 있는 젊은 청년들은 많이 있지만 아직까진 국 가 전체 산업이 개발되지 않은 상태라 일자리가 매우 부족 한 상황이다.

Table 1. 우간다의 직업별 노동인구 비율

\begin{tabular}{|c|c|c|}
\hline 농업 & 산업 & 서비스 산업 \\
\hline $71 \%$ & $7 \%$ & $22 \%$ \\
\hline
\end{tabular}

\section{우간다 교육 환경의 문제점}

앞서 살펴본 것 같이 우간다는 젊은 인력이 풍부한 국가 로 적절한 교육과 훈련이 지원되면 아프리카 대륙에서 성 장 가능성을 가지고 있는 국가이다. 때문에 우간다 정부에 서도 실력 있는 전문 인력 양성을 위해 국가 교육 시스템 을 보완, 발전시키기 위한 중장기 투자를 'Uganda Vision 2040' 발전 계획을 통해 시행하고 있다. 그러나 이러한 우 간다 정부의 노력에도 불구하고 농촌지역의 교육 환경은 쉽 사리 바뀌지 않고 있고 갈수록 도시-농촌 간 교육 불균형만 커지고 있다. 이러한 문제의 원인은 열악한 교육 인프라, 교 사 전문성, 빈곤, 진학률 등으로 정리해 볼 수 있다.

우선 농촌지역은 교육에 필요한 기본적인 인프라가 열악 하다. 농촌지역에 속한 다수의 초등, 중등학교들의 경우 대 부분 전기와 인터넷 사용을 할 수 없고 도서관, 실험실 등이 정상적으로 갖추어진 학교가 매우 드물다. 또한 오래된 학 교 건물에는 온전한 책걸상이 없기도 하고 대다수의 학교에 서는 교사, 학생 모두 교과서 없이 수업이 진행되고 있다.

다음으로 교사의 전문성 문제이다. 농촌지역에 속한 많은 국공립학교들의 경우 재정난이 심하여 정규 교사들의 월급 을 주지 못하는 경우가 빈번하다. 또한 도시에 비해 농촌 지 역에서 근무하는 교사들의 월급이 상대적으로 낮아 실력 있 는 교사를 모집하는 것이 매우 어렵다. 이로 인해 많은 학 교들이 비정규 교사를 고용하기도 하는데 이들의 경우 읽 기, 쓰기, 기초 수학 능력이 매우 부족하여 교육 환경에 부 정적인 영향을 주고 있다. 2016년 9월에 우간다 유력 일간 지의 기사에 따르면 초등과정 정규 교사 10 명 중 8 명이 정 부 시험 평가에서 읽기, 쓰기가 어려웠고 기초 수학 문제를 풀 수 없었다고 한다(Daily Monitor, 2016). 
빈곤은 앞서 설명한 인프라, 교사들의 전문성에도 영향을 주고 있는 문제다. 우간다 농촌지역의 경우 대부분이 자급 자족을 위한 농사를 업으로 알고 살아가는 사람들이 대부 분이어서 농사를 통해 새로운 가게 수입을 올리는 경우가 많지 않다. 농촌지역 가구의 한 달 평균 수입은 도시 지역 의 $50 \%$ 에도 미치지 못한다. 때문에 다수의 학생들이 학비 를 납부하지 못하고 있고 학교에서 필요한 학용품, 교과서 등도 구입하지 못하고 있다. 이런 문제는 결국 학생들의 학 업성취도에 부정적인 영향을 주어 학업을 중도에 포기하거 나 상급학교로의 진학을 포기하게 하였다.

다음은 앞서 설명했던 교육 환경의 문제점들이 어떤 원 인들로 심화되었는지 도시-농촌 간 경제, 교육, ICT 기술, 전 기 인프라 불균형을 통해 살펴보고 이런 문제들을 해결하 기 위한 IT4U ((Information Technology for Uganda) 교육센 터 사역에 대해 간략하게 소개하고자 한다.

Table 2. 월평균 가구 수입

\begin{tabular}{|c|c|}
\hline 국가 평균 월수입 & 416,000 실링 \\
\hline 도시지역 월수입 & 703,000 실링 \\
\hline 농촌지역 월수입 & 303,000 실링 \\
\hline
\end{tabular}

\section{1. 도시-농촌 간 경제 불균형}

위의 Table 2 에서와 같이 도시지역 가구 월평균 수입은 703,000 실링 (한화 230,000원), 농촌지역 가구의 월평균 수 입은 303,000 실링 (한화 100,000 원)으로 도시지역 가정의 월 평균 수입이 2 배 이상 높다. 국가 평균 가계 수입은 416,000 실링 (한화 135,000 원)으로 농촌지역의 가구 수입이 국가 평 균 가구 수입보다도 낮다(The Observer, 2017).

우간다 정부의 중장기 발전 계획에 따라 지속적으로 공 공기반 시설, 도시지역 주택 개발, 건설 산업, 도로망 건설, 제조업 등의 투자가 확대되고 있고 이로 인해 다양한 일자 리가 창출되고 있다. 그 결과로 도시지역의 경제는 활성화 되고 가구 수입도 증가하고 있지만 농촌지역은 이런 혜택 을 받지 못해 가구 수입 증가폭이 도시지역에 비해 낮다. 실 제로 농촌지역 거주민들은 대부분 자신의 땅에서 생산한 농 산물 중 자급자족하고 남은 소량의 잉여 물을 지역 시장 또 는 노점을 통해 판매하며 매우 적은 수입을 내고 있다.

\section{2. 도시-농촌 간 교육 불균형}

우간다 도시-농촌 간 교육 불균형은 2040년까지 현대화 된 중상위 국가로 도약하기 원하는 우간다 정부 계획에 큰 걸림돌이 될 수 있다. 우간다 정부도 이를 해결하기 위해 교 육체계를 보완하고 전국 학교들의 교육 환경을 발전시키기 위한 중장기 계획을 진행하고 있다.
우간다 교육체계는 유아교육 (Nursery) 2 3년, 초등교육 (Primary) 7년, 중등교육 (Secondary) 6년 그리고 고등교육 (Tertiary) 2 5년으로 구분된다. 중등교육은 4년 $\mathrm{O}$ 레벨 (Ordinary Level)과 2년 A 레벨 (Advanced Level)로 분류가 되는데 A 레벨을 졸업한 학생들에게 대학에 응시할 기회가 주어진다. 초등교육부터 중등교육 $\mathrm{O}$ 레벨까지 의무 교육이 고 각각의 교육 과정별로 정부에서 시행하는 졸업 시험을 통해 상급학교로의 진학이 결정된다. 정부에서 시행하는 인 증 시험은 초등과정을 위한 PLE (Primary Leaving Examination), O 레벨을 위한 UCE (Uganda Certificate of Education) 그리고 A 레벨을 위한 UACE (Uganda Advanced Certificate of Education)로 구성되어 있다. 각 교육 과정의 졸업 시험 은 매년 10 월 12월 사이 전국적으로 같은 날 시행되고 학 생들의 성적에 따라 결정된 학교 등급은 우간다 일간 신문 을 통해 발표된다.

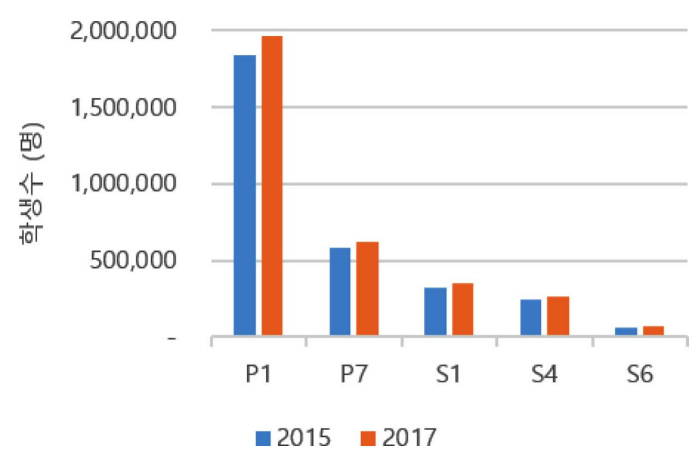

Figure 2. 2015, 2017년도 학년별 학생 수

과거 2011 2015년까지 시행되었던 초등과정 PLE 결과를 조사한 보고서에 따르면 그 기간 동안 PLE 합격률과 불 합 격률이 거의 비슷한 분포를 보이고 있다(Lee, 2017). 그 연 구 보고서에 따르면 농촌지역 학생들의 학업 성취도가 너 무 낮아 절대평가로 PLE 결과를 적용할 경우 대부분의 농 촌지역 학생들은 낮은 등급을 받아 상급학교로의 진학이 어 려울 수 있어 합격자 비율에 대한 강제 조정이 있었다고 설 명하고 있다. 이렇게 상급학교로 진학한 학생들의 경우 학 업 성취도가 낮기 때문에 중등교육 과정을 따라가지 못하 거나 가정의 경제적인 이유로 학업을 포기하게 된다. 실제 앞의 Figure 2의 그래프를 보면 2015년, 2017년 초등과정 1 학년 (P1)의 학생 수가 학년이 올라가면서 급격하게 감소하 는 것을 확인할 수 있다.

이처럼 의무교육 기간 동안 초등과정 및 중등과정을 이 수하지 못하고 상당수의 학생들이 이탈하고 있음을 확인할 수 있다. 특별히 이러한 상황은 농촌지역에서 더 많이 발생 하고 있다. 앞서 도시-농촌 간 경제 불균형에 대해 설명을 


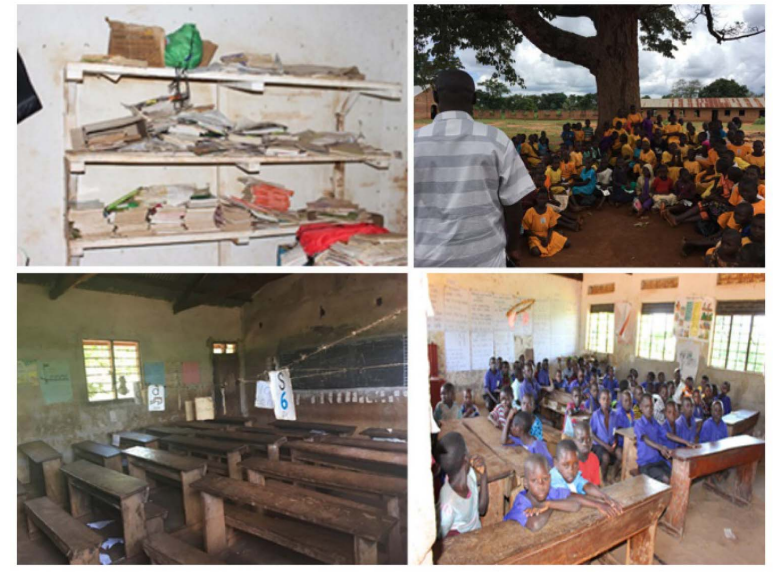

Figure 3. 농촌지역 학교의 도서관, 교실 현황

했지만 농촌 가구의 월평균 수입은 도시지역 가구의 $40 \%$ 수준이고 농촌지역의 평균 출산율이 5.9 명으로 도시지역 평 균 출산율 4.0 명보다 1.9 명이 많다. 즉, 농촌지역의 경우 도 시지역 가구보다 적은 한 달 수입으로 더 많은 가족들이 생 활을 한다. 때문에 농촌지역의 어린 학생들은 학교가 아닌 곳에서 가정의 생계를 위해 노동을 하거나 가사를 돕는 경 우가 빈번하다. 이러다 보니 농촌지역 학부모, 학생들의 경 우 학업에 대한 필요성 보다 생계에 대한 필요성을 더 크 게 느끼고 있다. 또한 도시-농촌지역 교사들 간의 월급 격 차가 커서 대다수의 실력 있는 교사들은 대부분 도시지역 학교에서 근무하고 있고 농촌지역 학교들의 경우 정교사를 구하지 못해 비정규직 교사들을 다수 고용하고 있다. 그뿐 만 아니라 낮은 가구 수입으로 인해 학생들이 교과서를 구 입하지 못하는 경우가 많고, 실제 농촌지역 다수의 학교들 에서 학생들은 교과서 없이 수업을 진행하고 있다. Figure 3 을 보면 농촌지역 학교들의 교육 환경이 얼마나 열악한지 알 수 있다. 이러한 이유로 도시-농촌 간 교육 불균형은 더 욱더 심화되고 있으며 경제적인 문제뿐만 아니라 다음에 설 명할 인터넷 문제, 전기 문제 등도 도시-농촌 간 교육 불균 형을 가속시키고 있다.

\section{3. 도시-농촌 간 ICT 기술 불균형}

우간다의 경우도 ICT 기술을 국가 성장 동력으로 활용하 기 위한 기술 개발, 인프라 구축, 정책 개발 등을 위한 투 자를 늘리고 있다.

위의 Figure 4는 2019년에 조사된 아프리카 주요 국가들 의 도시-농촌 간 인터넷 서비스 사용자를 비교 분석한 그래 프이다(Research ICT Africa, 2019). 조사된 내용을 보면 다 른 아프리카 주요 국가들처럼 우간다도 도시-농촌 간 인터 넷 서비스 사용자 비율에서 상당한 차이가 있는 것을 확인

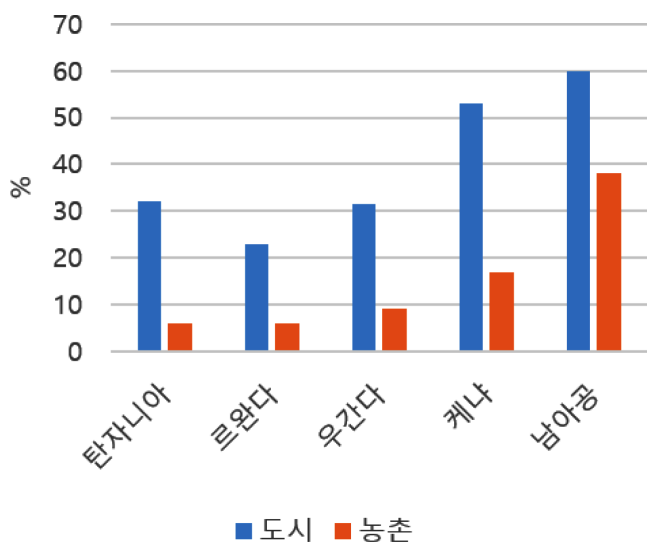

Figure 4. 도시-농촌 간 인터넷 서비스 사용현황

할 수 있다. 우간다의 경우 전체 인구 가운데 $40 \%$ 정도만 이 인터넷 서비스를 사용하고 있으며 그중 $31 \%$ 가 도시에 서, 나머지 $9 \%$ 가 시골지역에 인터넷 서비스를 사용하고 있 다. 이렇듯 전체 인터넷 서비스 사용 인구도 적지만 특히 농 촌 지역에서 인터넷 서비스 사용자 수가 낮은 것을 볼 수 있다. 여기에는 다양한 이유가 있겠지만 그중 유선 네트워 크 환경 부족과 비싼 데이터 비용 그리고 교육 문제 등을 들 수 있다.

다음 Figure 5는 우간다서 2015년부터 현재까지 진행되고 있는 국가 백본 인프라 구축 사업의 결과들로 설치된 광케

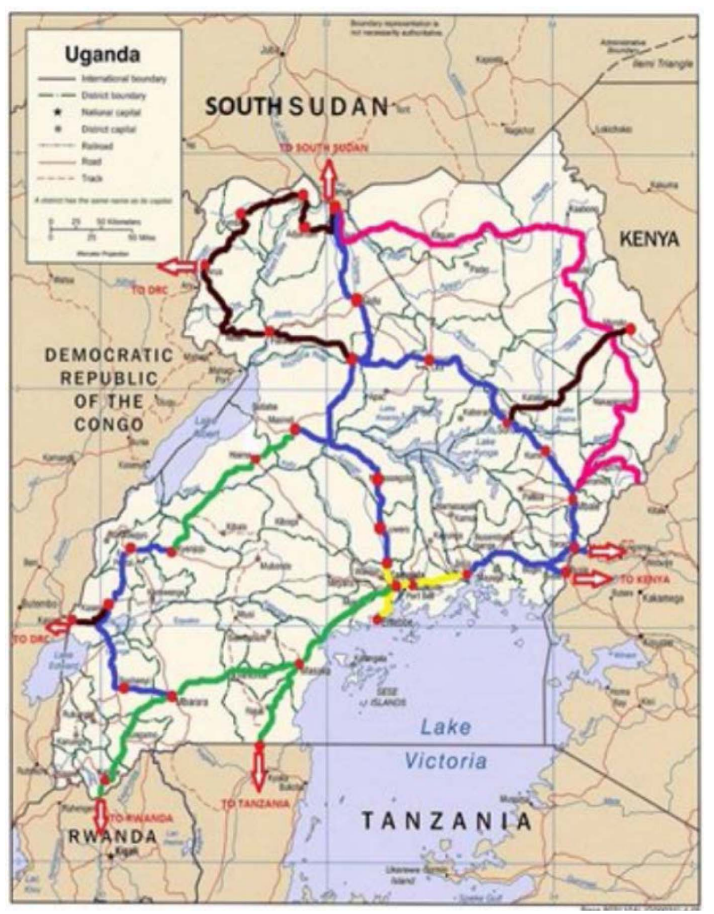

Figure 5. 국가 백본망 구축 현황

(National Information Technology Authority Uganda, NITA) 
이블 구조도를 보여주고 있다(NITAU, 2009). 현재 4단계까 지 사업이 완료되었고 마지막 5단계 사업이 진행되고 있다. 아직 설치된 광케이블을 이용한 인터넷 서비스가 일반인들 에게 공개되지 않았지만 5단계 사업이 진행된 이후 이를 이 용한 다양한 인터넷 서비스가 개발될 것으로 예상된다. 때 문에 현재 인터넷을 사용하는 사람들 대부분은 $3 \mathrm{GPP} 2$ 나 $4 \mathrm{G}$ 등의 이동 통신망을 통해 무선 인터넷 서비스를 사용하고 있지만 대부분의 기지국이 도시지역에 밀집되어 있어 농촌 지역의 경우 인터넷 접속이 쉽지 않고 속도 또한 평균 $256 \mathrm{kbps} \sim 1 \mathrm{Mbps}$ 로 느리다.

두 번째 도시-농촌 간 인터넷 서비스 접속자 차이가 크게 나는 이유는 데이터 비용이 비싸기 때문이다. 아직은 우간 다에서 유선 네트워크를 이용한 인터넷 서비스 사용이 어 렵다. 국가기관, 은행, 특정 대학교, 기업 등에서 유선 인터 넷 서비스를 소수 사용하고 있지만 대부분은 이동 통신망 을 통해 무선 인터넷 서비스를 사용하고 있다. Figure 6은 우간다의 주요 이동통신 기업인 MTN (Mobile Telecommunications Network)에서 제공하는 3GPP2와 LTE 서비스 지역 을 표시한 것이다(MTN, 2021). 그림에서 확인할 수 있는 것 처럼 LTE 서비스는 주요 도시지역에 밀집되어 있고 그 외 지역의 경우 $3 \mathrm{GPP} 2$ 서비스만 제공되고 있는 것을 알 수 있 다. 농촌지역의 경우 이동 통신망에서의 인터넷 사용 비용 이 비싸기 때문에 특별한 경우가 아니면 인터넷 서비스를 사용하지 않고 있다.

세 번째는 인터넷 활용 교육 문제를 들 수 있는데 시골 지

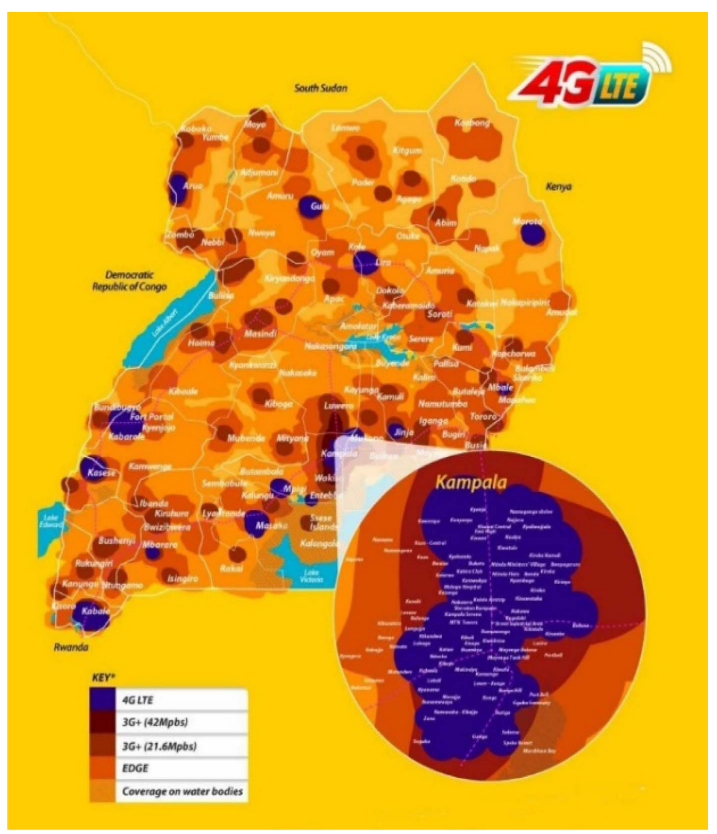

Figure 6. MTN 서비스 제공 지역 (Mobile Telecommunications Network Map, MTN)
역의 경우 교육 과정을 통해 인터넷 서비스를 배울 수 있 는 기회가 없다. 도시 지역에 비해 관련 인프라가 너무도 부 족하기 때문에 많은 어린 학생들은 컴퓨터 자체를 만질 수 도 없고, 활용 방법 등도 습득하지 못하고 있다. 또한 성인 들의 경우도 평생 동안 컴퓨터를 만져보지 못한 사람들이 다수이기 때문에 인터넷에 대해 무지하거나 관심이 없는 경 우가 대부분이다. 그러나 도시지역의 경우 농촌지역에 비해 비용을 지불하면 어디서든 자유롭게 인터넷 서비스를 사용 할 수 있는 인프라가 구축되어 있다. 결국 이러한 차이가 도 시-농촌 간 ICT 기술의 불균형을 가져왔고 농촌지역 학생 들의 교육 환경에도 부정적인 영향을 주었다.

\section{4. 도시-농촌 간 전기 인프라 불균형}

2018년 월드뱅크에서 조사한 결과를 보면 전기 사용 가 능 인구는 전체 인구 중 $42.65 \%$ 정도이고 이중 $57.5 \%$ 는 도 시지역, $38 \%$ 는 시골지역에서 전기 사용이 가능한 것으로 조 사되었다(The World Bank, 2021b). 다음의 Table 3은 2019 년 전체 인구 대비 전기 사용자 비율을 조사한 것으로 2018 년에 비해 전체 전기 사용 인구가 $42.65 \%$ 에서 $55 \%$ 로 증가 한 것을 확인할 수 있다.

Table 3. 전체 인구대비 전기 사용 현황

\begin{tabular}{|c|c|c|c|}
\hline 전기미사용 & 전기사용 & 태양전지 & 기타 \\
\hline $45 \%$ & $18 \%$ & $25 \%$ & $12 \%$ \\
\hline
\end{tabular}

앞의 Table 3 을 살펴보면 메인 전기 사용자가 $18 \%$ 로 다 른 방법을 통해 전기를 사용하는 인구보다 작다는 것을 볼 수 있다. 우간다의 경우 도시와 농촌지역의 주거지 환경이 매우 다르다. 주거지가 밀집되어 있는 도시와는 다르게 우 간다 농촌지역의 경우 가구와 가구 간의 거리가 수백 미터 에서 수 키로까지 떨어져 거주하고 있다. 때문에 농촌지역 각 가정에 메인 전기를 공급하기 위해서는 막대한 설비투 자 비용이 요구되어 쉽사리 전기를 공급하지 못하고 있다. 또한 이러한 상황은 농촌지역에 위치한 초등, 중등학교에서 도 동일하게 보이고 있는데 학교까지 전기를 연결하는 문 제가 쉽지 않고 전선이 학교까지 연결되었다 하더라도 비 용 문제로 전기를 사용하지 않고 있다. 이런 문제는 결국 농 촌지역 학교의 교육 환경 질을 낮추게 되고 학생들의 학업 성취도에도 부정적인 영향을 주게 되어 도시-농촌 간의 교 육 불균형을 더욱 가속시키고 있다.

앞서 설명한 문제들은 단기간에 해결할 수 없고 막대한 재정을 필요로 한다. 그뿐만 아니라 지속적인 인식 변화를 위한 꾸준한 교육 지원이 필요하고 농촌지역의 경제 자립 을 위한 외부 도움 및 거주민들의 자발적인 노력이 필요하 
다. 이에 IT4U 교육센터에서는 여러 문제 영역 가운데서 교 육 분야의 문제점들을 분석하였고 도시-농촌 간의 교육 불 균형을 줄여갈 수 있는 방안을 고민하며 몇 가지 사업을 수 행하고 있다. 진행되고 있는 사업은 특별히 교사들의 인식 변화, 역량 강화에 초점을 두고 있으며 교육받은 교사들이 스스로 자신들의 역량을 지속적으로 강화할 수 있도록 지 원하고 있다.

다음은 이런 우간다 상황에서 ICT 기술 지원을 통해 농 촌지역 교육 환경을 개선하고 학생들의 교육 성취도를 높 이고자 진행하고 있는 몇 가지 활동들을 소개하고자 한다.

\section{도시-농촌 간 교육 불균형을 줄이기 위한 ICT 적정기술}

IT4U (Information Technology for Uganda) 교육센터는 우 간다 도시-농촌 간 교육 불균형을 줄여 어느 지역, 누구라 도 평등한 교육을 받을 수 있도록 ICT 기술을 지원하기 위 해 설립되었다. 앞서 설명했던 것처럼 우간다 도시-농촌 간 교육 환경 불균형은 사회의 복합적인 문제들이 만들어낸 것 으로 어느 한 부분만 발전한다고 해서 해결될 수 있는 것 은 아니다. IT4U 교육센터는 효과적이고 지속 가능한 ICT 기술 지원을 통해 우간다 정부 지원 사각지대를 보완하여 농촌지역 사회에 도움이 되고자 사업을 진행하고 있다.

IT4U 교육센터에서 지원하고 있는 사업은 크게 ICT 실무 전문가 양성사업과 교사 재교육 및 양성 사업으로 구분할 수 있다. ICT 실무 전문가 양성사업은 SW 실무 개발자, 네 트워크 설계 및 구축 가능한 실무 전문가 양성과 대학의 ICT 과목 강의를 지원하고 있으며, 농촌지역의 열악한 교육 환 경을 고려한 모바일 교육 센터 사업을 진행하고 있다. 모바 일 교육 센터는 전기, 인터넷, 교과서 등이 준비되지 않은 농촌지역 학교들에서도 다양한 교육 활동 및 교사 역량 강 화 교육을 지원하기 위해 차량을 개조하여 태양전지 및 여 러 ICT 장비를 장착한 후 직접 학교를 방문하여 교육을 진 행하는 사업으로 필요한 차량 구입을 위한 후원자를 기다 리고 있다. 교사 재교육 및 양성 사역은 초등, 중등학교의 과학, 수학, ICT 교사의 역량 강화 교육을 지원하고 더불어 미래 교사 양성을 지원하는 사업이다. 이 사업을 위해 한국 의 교육대학교, ICT 벤처기업, $\mathrm{NGO}$ 및 다수의 실무 전문 가들이 도움을 주고 있다.

2020년 3월 우간다서 처음 코로나19 환자가 발생한 후 3 월 말부터 국가 봉쇄 조치가 시작되었다. 국가 봉쇄 조치로 전국의 모든 유치원부터 대학들이 문을 닫았었고 2021년 4 월부터 졸업반 과정을 시작으로 학교 수업이 조금씩 시작 되었다. 아직 정상화되지 않은 과정들은 6월 이후부터나 수

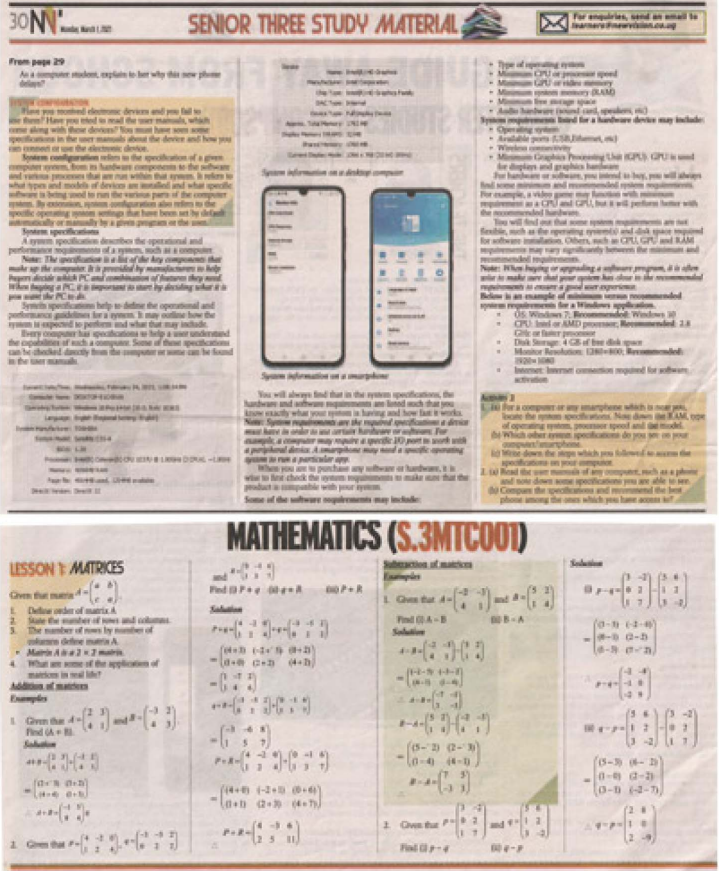

Figure 7. 일간 신문에 배포되는 교육자료 (New Vision News Paper, New Vision)

업이 진행될 예정이나 다시 코로나 확진 자가 증가하고 있 는 상황에서 정부가 어떻게 결정할지 알 수 없는 상황이다.

국가 봉쇄 조치로 수업이 진행되지 않자 우간다 정부에 서는 비대면 수업이 진행될 수 있도록 여러 방안을 마련했 었다. TV와 라디오를 통한 교육 방송을 준비했었으나 농촌 지역 가정들 대부분이 전기 사용이 어렵고, TV 나 라디오 가 없어 시행에 어려움을 겪었다. 정부에서 모든 가정에 라 디오를 공급하려 했다가 재정상의 이유로 시행되지 않았다. 그 이후 앞의 Figure 7과 같이 일간신문을 통해 교육 자료 를 배포하고 있지만 이 또한 농촌지역의 경우 일간 신문 구

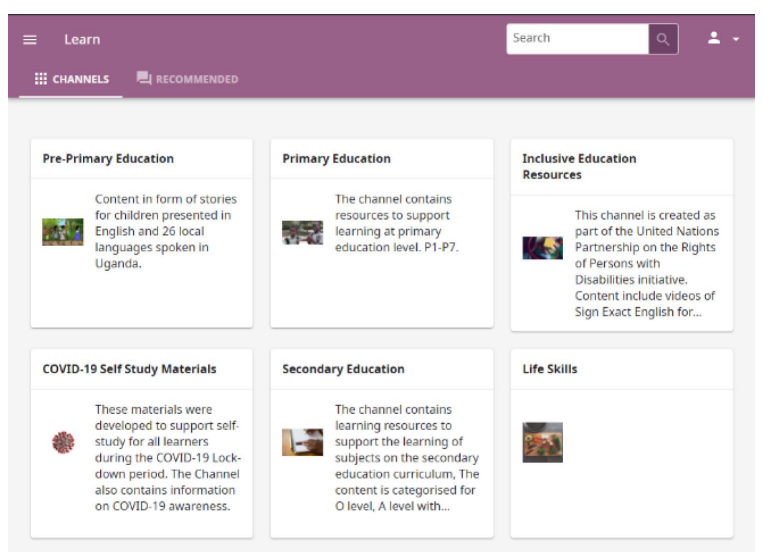

Figure 8. 온라인으로 배포되는 교육자료 


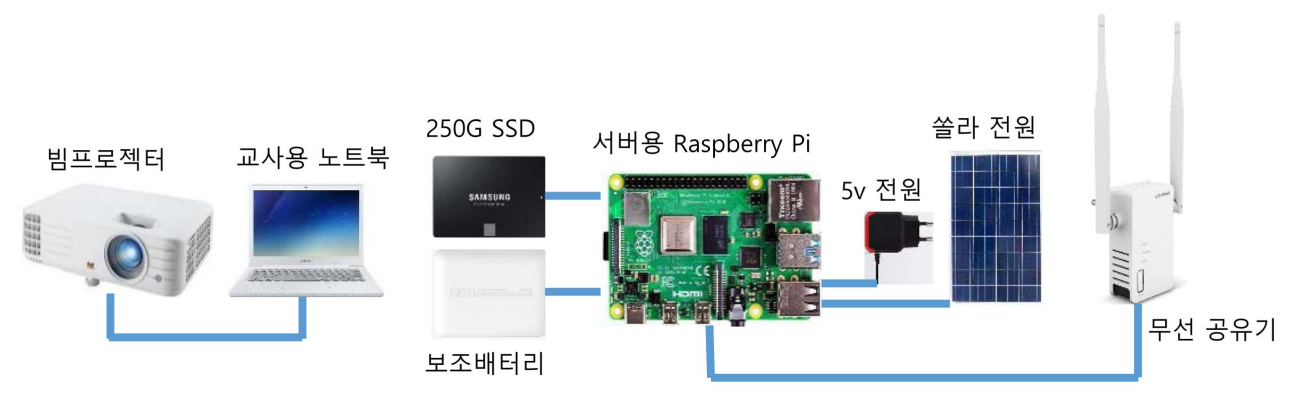

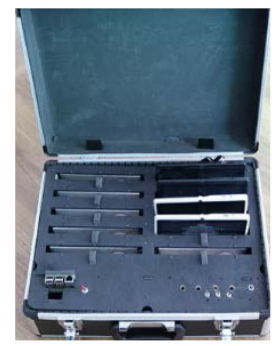

태블릿 무선 충전 및 보관용 박스

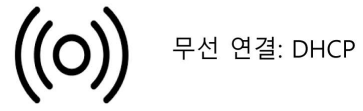
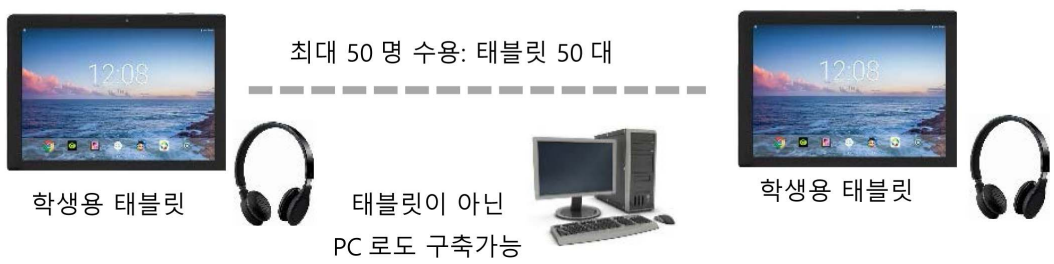

Figure 9. WAINBOX를 이용한 멀티미디어 교실 구조도
려워 농촌지역에서는 도움이 되지 않고 있다.

현재는 우간다 교육부에서 유니세프의 도움을 받아 Figure 8과 같은 웹페이지를 만들어 교육 콘텐츠를 업로드 및 배포하고 있다(MES, 2020). 그러나 이 모든 것도 인터 넷 접속이 가능한 가정들만 사용할 수 있고 농촌지역의 대 다수 가정들은 인터넷 접속 자체가 어려워 큰 효과를 보지 못하고 있다. 이런 이유들로 지난 1 년 동안 농촌지역에 거 주하는 대다수의 학생들은 교육을 받지 못했고 이를 보강 하기 위한 계획을 교육부에서 논의하고 있다.

이런 상황에서 IT4U 교육센터에서는 인터넷 연결 없이도 충분한 멀티미디어 교육 콘텐츠를 사용할 수 있도록 전자 도서관 시스템을 적용한 멀티미디어 교실을 Figure 9와 같 이 구성하여 보급하는 사역을 코로나19가 발생하면서부터 준비하여 진행하고 있다. 전자도서관 시스템은 이미 수년 전 부터 제 3 세계 여러 국가들에서 사용되고 있는 RACHEL (Remote Area Community Hotspot for Education and Learning) 이라는 오픈소스를 기반으로 GLH (God Love House) 교육 지원연구소와 함께 개발하였다(World Possible, 2008). IT4U 교육센터에서 개발한 전자도서관 시스템은 다음의 Figure 10 과 같이 WAINBOX (Worldwide Academy in a Box)라는 이름으로 보급되고 있고 우간다뿐만 주변 아프리카 국가들 , 동남아시아 및 중앙아시아 국가들에 보급하고 있다.

개발된 WAINBOX에는 라즈베리 파이 4B 모델에 RACHEL, Kolibri, Moodle, 워드프레스 그리고 SSD $250 \mathrm{G}$ 하드와 별 도의 무선 공유기가 장착되어 있다. 또한 전기 사용을 못 하

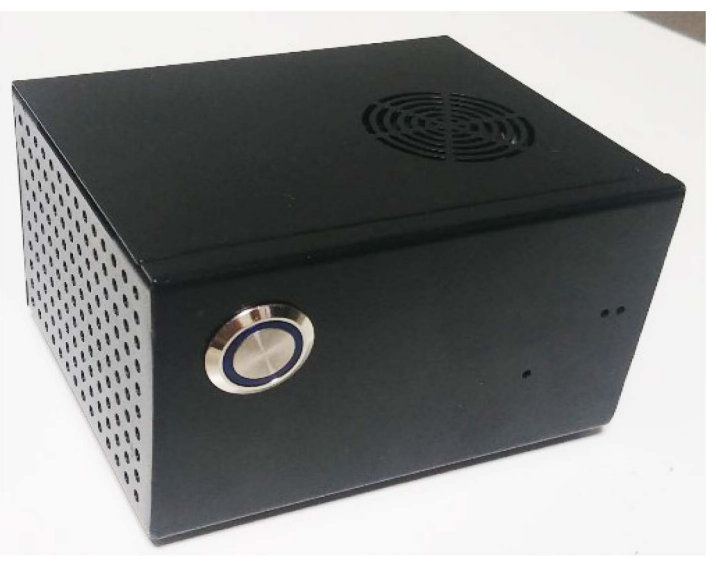

Figure 10. WAINBOX

는 곳에서도 사용할 수 있도록 태양전지 연결 버전으로 보 완하고 있다. 현재까지 개발된 WAINBOX는 10 인치 태블릿 $\mathrm{PC}$ 45대를 동시 연결한 상태에서 멀티미디어 교육 콘텐츠 를 무리 없이 사용할 수 있는 것까지 테스트 완료하였다. 이 렇게 개발된 WAINBOX는 IT4U 교육센터를 통해 우간다 농 촌지역 학교에 보급될 예정이다. 지난 3 월 우간다 쿠미 지 역 초등학교 2곳을 시범학교로 선정하였고 5월 중 WAINBOX 설치 및 현지 교사 역량 강화 교육을 진행할 예정이다.

WAINBOX에는 방대한 양의 교육 콘텐츠가 저장되어 있 어 농촌지역 학교들의 열악한 교육 환경을 개선하는 데 도 움이 될 수 있다. 그러나 우간다 현지 사정상 이런 장비를 지원한다고 해서 우리가 예상하는 것처럼 해당 학교들이 자 
발적으로 교육 콘텐츠를 수업에 활용하거나 필요한 교육 콘 텐츠를 만들어 학생들에게 제공하는 활동을 하지 않는다. 선 생님들과 학생들 모두 오랫동안 ICT 기술을 자주 접하지 못 했고 일상에서도 컴퓨터, 인터넷, 전기 등을 쉽게 접하지 못 했기 때문에 어떻게 사용해야 하는지, 사용했을 때 어떤 유 익이 있는지에 대한 경험이 없다. 그렇기 때문에 ICT 기술 지원과 더불어 교사들의 인식 변화를 위한 교육이 지속적 으로 지원되어야 한다. IT4U 교육센터에서는 WAINBOX를 지원하는 학교들을 대상으로 계속 진행되고 있는 교사 ICT 역량 강화 교육과 더불어 WAINBOX 사용법, 교육 콘텐츠 활용방법, 교사 인성 교육 그리고 교수법 등을 관련 전문가 들과 협업을 통해 진행하게 된다.

앞서 설명한 WAINBOX에는 RACHEL에서 제공되고 있 는 다양한 무료 교육 콘텐츠 이외에도 전주교육대학교의 도 움을 받아 초등학교 교과 과정인 영어, 과학, 수학 과목에 대한 교육 콘텐츠 영상, 파워포인트 자료, 수업 계획서 등 이 영어로 제작되고 있다. 이미 전체 초등과정 $\mathrm{P} 1 \sim \mathrm{P} 7$ 중 P2 P5 과정이 마무리되었고 올해 안에 나머지 과정에 대한 교육 컨텐츠 제작도 마무리될 예정이다. 이렇게 제작된 교 육 콘텐츠는 WAINBOX에 탑재되어 우간다 현지 초등학교 들에 지속적으로 보급될 것이다. 현재까지는 WAINBOX와 40 50인치 LCD TV만 지원하고 있지만 학생들이 상시 WAINBOX에 접속하여 자기주도 학습이 가능한 시스템을 구축하기 위해 여러 가지 아이디어를 논의하고 있다. 특별 히 개별 학생들을 위한 인터넷 접속 가능한 단말을 저렴하 게 보급하는 방법과 가정에서도 쉽게 사용할 수 있는 전기 시스템을 저렴하게 보급하기 위한 논의를 진행하고 있다. 이 미 개발된 적정기술들이 있지만 우간다 농촌지역에 직접 보 급하기엔 여러 가지 문제점들이 있어 보완작업이 필요하다.

\section{향후 활동 계획}

IT4U 교육센터는 다음과 같이 ICT 적정 기술을 우간다 농 촌지역에 보급하여 도시-농촌 간 심화된 교육 불균형을 지 속적으로 줄여가고자 활동 범위를 넓혀가고 있다. 향후에는 현재 진행하고 있는 사업의 대상 지역 및 학교를 확대하여 더 많은 학교들이 혜택을 받을 수 있도록 추진함과 동시에
다음의 항목들과 같은 사업을 수행할 수 있도록 내부 역량 을 강화하고, 인적, 물적 네트워크를 확대하여 더 많은 농 촌지역에 도움을 주고자 한다.

- 향후 진행 사업

ㅁ 라즈베리 파이를 이용한 학생용 단말 지원 사업

ㅁ 가정용 친환경 발전기 지원 사업

ㅁ 마을 공장 및 전산센터 지원 사업

\section{References}

Daily Monitor. (2016). https://www.moni tor. co.ug/uganda/news/ national/video-government-admits-80-of-teachers-can-t-read1667658 (accessed Mar. 2021)

Lee, M. C. (2017). To Drive the Method for Rebuilding Education System based on ICT Application in Africa Refuge Camo, pp. 6-9.

Ministry of Education \& Sports (MES). (2020). http://e-learning.education.go.ug/en/learn/\#/ topics/ (accessed Mar. 2021)

Mobile Telecommunications Network (MTN). (2021). https:// www.mtn.co.ug/insight/coveragemap/ (accessed Mar. 2021)

National Information Technology Authority - Uganda (NITA-U). (2009). https://www.nita.go.ug/search/node/backbone/ (accessed Mar. 2021)

National Planning Authority (NPA). (2002). http://www. npa.go.ug/ uganda-vision-2040/ (accessed Feb. 2021)

Research ICT Africa. (2019). The State of ICT in Uganda, IDRC and SIDA, pp.8-24.

The Observer. (2017). https://obser ver.ug/ business/55252-subsistence-farming-tops-local-sources-of-income.html\#: :text= Overall $\% 2 \mathrm{C} \% 20$ the $\% 20$ average $\% 20$ monthly $\% 20$ cash, Central\%20I\%20at\%20Shs\%20569\%2C000. (accessed Dec. 2020)

The World Bank. (2021a). https://data.worldbank.org/country/ uganda?view $=$ chart $/($ accessed Mar. 2021)

The World Bank. (2021b). https://data.worldbank.org/indicator/ EG.ELC. ACCS.ZS?locations=UG (accessed Mar. 2021)

World Possible. (2008). https://store.worldpossible.org/collections/Rachel/ (accessed Oct. 2020) 